\title{
PAMIĘĆ PROTETYCZNA I NIEREALNOŚĆ CZASU W SERIALU WATCHMEN
}

\author{
Prosthetic Memory and Unreality of Time in Watchmen
}

\begin{abstract}
Starting from a reflection on the traumatic experience of racism, the author of the article considers the possibility of transmitting the knowledge about the past and retrieving memory, and then points out how the relationships between the past, the present and the future are problematized, if we change the way we think about time, namely when it ceases to be perceived as something real or objective. The point of reference for further considerations is the HBO Watchmen series, made in 2019, which exemplifies the mechanism of prosthetic memory. According to the definition proposed by Alison Landsberg, prosthetic memory includes continuity and rupture. It is connected not only with the individual but the collective dimension as well, as it is related to the sphere of politics. In other words, it is a vehicle thanks to which we can travel to other places and times, and thanks to which the viewer may refer to important social and psychological issues.
\end{abstract}

Keywords: trauma studies, prosthetic memory, television series, graphic novels, eternalism and philosophy of time

1 czerwca 1921 roku w Tulsie, drugim co do wielkości mieście stanu Oklahoma, który czternaście lat wcześniej został przyjęty do Unii, wybuchły zamieszki na tle rasowym. Kilkuset uzbrojonych białych mężczyzn wkroczyło do dzielnicy Greenwood, zamieszkałej przez mniejszość afroamerykańską, pod pozorem przywrócenia porządku i obrony gmachu sądu przed thumem protestujących, którzy domagali się uwolnienia czarnoskórego nastolatka oskarżonego o gwałt na białej dziewczynie. Podobno dzień wcześniej w godzinach wieczornych doszło do strzelaniny i śmierci jednego ze strażników. Chcąc zapobiec eskalacji przemocy, policja wezwała posiłki - na miejsce przybyła Gwardia Narodowa i rozbroiła mieszkańców Greenwood, wśród których znalazło się wielu weteranów wojennych. W nocy rozpętało się prawdziwe piekło, ponieważ biali najpierw podłożyli ogień pod liczne budynki, a potem zaczęli strzelać do ludzi uciekających z pożaru. O świcie nad miastem przeleciał 
dwupłatowiec, przygotowując się do ataku z powietrza. Susan Williams, współwłaścicielka Dreamland Theatre, zeznała potem w sądzie, że widziała, jak podpalano jej dom i mordowano bezbronnych ludzi, podobne zeznanie złożył również Ottowa W. Gurley, właściciel spalonego hotelu i lider lokalnej społeczności. Według oficjalnych danych w starciach zginęło co najmniej 25 osób i spłonęło 35 budynków, jednak w statystykach nie ujęto zwłok wywożonych w ciężarówkach, dlatego przyjmuje się, że ofiar było kilkakrotnie więcej (od 75 do 150 osób) ${ }^{1}$.

Damon Lindelof, pomysłodawca i scenarzysta serialu Watchmen (2019), zainspirowany watkami i postaciami z komiksu Alana Moore'a i Dave'a Gibbonsa, wydawanego przez DC Comics w latach 1986-1987, postanowił zacząć pierwszy odcinek od przywołania historii sprzed stu lat. Kilkuminutowa sekwencja inicjalna stanowi stylizowaną rekonstrukcję zamieszek, opartą na dokumentacji fotograficznej i wspomnieniach świadków, choć twórcy zdecydowali się na wyodrębnienie szczególnego miejsca, mianowicie budynku Dreamland Theatre - jednego z dwóch kin działających w Greenwood. Chodziło im przede wszystkim o podkreślenie uprzywilejowanej roli obrazów w przywracaniu pamięci o przeszłości i budowaniu więzi międzypokoleniowej, lecz także o wyróżnienie filmu jako narzędzia kształtowania tożsamości zbiorowej, pozwalającego widzom przeżyć to, czego w inny sposób nie mogliby doświadczyć2 . $^{2}$

Traumatyczne wydarzenia pokazane są w pierwszej sekwencji z perspektywy dziecka, co niesie z sobą określone konsekwencje. Siedmioletni Will Williams (Danny Boyd Jr.) jest jednym z nielicznych widzów na popołudniowym seansie - jak zwykle towarzyszy matce, która pracuje w kinie jako taper (gra na pianinie). Chłopiec ogląda swój ulubiony film Zaufaj prawu! (Trust in the Law!), wyreżyserowany przez Oscara Micheaux, o zamaskowanym mścicielu Bassie Reevesie - „czarnym szeryfie z Oklahomy"3. Nie zdaje sobie sprawy z tego, że na zewnątrz trwają rozruchy, które zakończą się tragicznie dla jego bliskich. Wywieziony z miasta przez znajomych ojca, przeżyje jako jedyny członek rodziny i po latach wstapi do szkoły policyjnej, by - jak bohater $\mathrm{z}$ dzieciństwa - pilnować prawa i porządku. W jego ślady pójdzie wnuczka, Angela Abar (Regina King), bohaterka serialu Watchmen, ukrywająca się pod pseudonimem Siostra Noc.

1 Szczegółowy opis przebiegu wydarzeń podaje Alfred L. Brophy w książce Reconstructing the Dreamland: The Tulsa Riot of 1921, Oxford University Press, New York 2002.

2 Annette Kuhn zauważyła, że „kino jest zdolne nie tylko do odtwarzania samej czynności zapamiętywania [...], lecz również do łączenia osobistych doświadczeń z szerszymi procesami pamięci kulturowej” (Memory Texts and Memory Work: Performances of Memory in and with Visual Media, „Memory Studies" 2010, Vol. 3, No. 4, s. 303).

3 Oscar Micheaux (1884-1951) był pierwszym afroamerykańskim reżyserem i niezależnym producentem, nakręcił ponad 40 filmów niemych i dźwiękowych, jednak Zaufaj prawu! to dzieło wymyślone przez twórców serialu. Postacią autentyczną jest natomiast bohater tego filmu, czyli Bass Reeves (1838-1910), który w ciągu długiej kariery aresztował podobno 3 tysiące przestępców. Urodził się w stanie Arkansas, w rodzinie niewolników, po wybuchu wojny secesyjnej wstąpił do wojsk konfederackich, a w 1878 roku został zastępcą szeryfa na terytoriach położonych na zachód od rzeki Missisipi. 
Sekwencja inicjalna, którą można potraktować jako rodzaj wydarzenia granicznego i traumy założycielskiej ${ }^{4}$, określa jeden z podstawowych tematów serialu, mianowicie wpływ przeszłości na teraźniejszość, ale jednocześnie - poprzez zestawienie z kolejnymi scenami - uświadamia nam, że ciagłość i linearność opowieści nie pasują do narracji traumatycznej, że jedynym sposobem na przedstawienie tego, co nieprzedstawialne, jest epizodyczność i wielogłosowość. Dominick LaCapra stwierdził, że w aspekcie politycznym trauma założycielska „może być sposobem na odzyskanie historii i przekształcenie jej w mniej lub bardziej sankcjonujące podstawy życia w teraźniejszości" ${ }^{\prime}$. Patrząc na to z drugiej strony, traumatyczne wydarzenia, które są wciąż na nowo przeżywane, prowadzą do niemożności wyzwolenia się spod władzy przeszłości. Masakra, do jakiej doszło sto lat temu w Tulsie, przez długi czas pozostawała w zapomnieniu, zepchnięta gdzieś na margines, wymazana z oficjalnego dyskursu. Nie opisywano jej w podręcznikach historii ani nie pokazywano na ekranie kinowym, co do pewnego stopnia można tłumaczyć naturą pamięci traumatycznej, która wiąże się z „opóźnioną czasowością i okresem latencji”.

Wychodząc od refleksji nad traumatycznym doświadczeniem rasizmu, chciałbym zwrócić uwagę na możliwość przekazywania wiedzy o przeszłości i odzyskiwania pamięci, a następnie pokazać, w jaki sposób związki łączące przeszłość, teraźniejszość i przyszłość ulegają problematyzacji za sprawą zmiany sposobu myślenia o czasie, który przestaje być postrzegany jako coś istniejącego realnie czy obiektywnie. Pragnę zacząć najpierw od pytania, które zadała niegdyś Marianne Hirsch, o to, kto ma sprawować pieczę nad traumatyczną przeszłością pokoleń i jak przechowywana jest pamięć o tragicznych wydarzeniach ${ }^{7}$. Amerykańska badaczka zwróciła uwagę na uprzywilejowaną rolę rodziny jako miejsca przekazywania wspomnień oraz fotografii jako materialnego śladu, pozostałości po tych, którzy odeszli. Nie tylko zdjęcia, lecz także filmy i seriale telewizyjne pozwalają przyjrzeć się bezpowrotnie utraconej przeszłości, stają się narzędziami umożliwiającymi wgląd w wydarzenia, w których bezpośrednio nie brało się udziału, a także swoistymi katalizatorami w dyskusjach na temat historii.

Obrazy filmowe stanowią rodzaj pamięci protetycznej - by posłużyć się określeniem Alison Landsberg - ponieważ dzięki nim człowiek zyskuje zdolność nabywania nowych wspomnień oraz nawiązywania głębszego, bardziej osobistego kontaktu z odległa przeszłością․ Pamięć protetyczna zawiera w sobie ciagłość i zerwanie, łączy się nie tylko z wymiarem jednostkowym, ale i zbiorowym (ma związek

4 Pojęć ,wydarzenie graniczne” i „trauma założycielska” używam w znaczeniach nadanych im przez Dominicka LaCaprę w książce Historia w okresie przejściowym. Doświadczenie, tożsamość, teoria krytyczna, przeł. K. Bojarska, Universitas, Kraków 2009.

Ibidem, s. 78.

Ibidem, s. 155.

M. Hirsch, Pokolenie postpamięci, przeł. M. Borowski, M. Sugiera, „Didaskalia” 2011, nr 105, s. 28.

8 Zob. A. Landsberg, Prosthetic Memory: The Transformation of American Remembrance in the Age of Mass Culture, Columbia University Press, New York 2002, s. 2. 
z płaszczyzną polityczną), jest wehikułem, dzięki któremu przenosimy się w inne miejsca i inne czasy. Jej działanie objawia się w szczególny sposób na poziomie doznań afektywnych, wywołanych przez iluzję partycypacji i odbieranych zmysłowo przez ciało?.

Jednym ze sposobów przedstawienia pamięci zapośredniczonej w serialu Watchmen są rozbudowane sekwencje retrospekcyjne w odcinkach szóstym i siódmym, w których główna bohaterka - po zażyciu zakazanych pigułek o nazwie Nostalgia zyskuje dostęp do wspomnień dziadka (Louis Gossett Jr. i Jovan Adepo). Nie chodzi bynajmniej o możliwość ,zobaczenia” tego, co widział Will Williams, lecz o doznania somatyczne, swoiste ożywienie emocji, jakie towarzyszyły w danej chwili mężczyźnie. Bohaterka uświadamia sobie, że jej czas „wypadł z kolein”, że przeszłość miesza się z teraźniejszością - to wywołuje dezorientację i niepewność co do ontologicznego statusu wydarzeń, w których (bez)pośrednio bierze udział. Angela przeżywa wszystkie momenty zwrotne w życiu dziadka: przedwczesną śmierć rodziców, strach z powodu opuszczenia, dzień ukończenia szkoły policyjnej, codzienne zmaganie się z rasizmem w pracy i na ulicy, pobicie przez kolegów z posterunku, a wreszcie decyzję o przeciwstawieniu się przemocy i walce $\mathrm{z}$ przestępczością $\mathrm{w}$ przebraniu Zakapturzonego Sędziego. W ciągu kilku miesięcy tajemniczy mężczyzna w kapturze ze sznurem zawieszonym na szyi stał się wzorem do naśladowania dla innych zamaskowanych mścicieli, którzy w 1939 roku założyli stowarzyszenie o nazwie Gwardziści (Minutemen) ${ }^{10}$.

Jeśli zgodzimy się, że pamięć protetyczna przekazywana jest na poziomie afektywnym, to możemy uznać, że w procesie przywoływania wspomnień zawsze wychodzimy od doznań cielesnych ${ }^{11}$. Ciało jest nośnikiem pamięci, a zarazem miejscem krzyżowania się różnych płaszczyzn czasowych, co w serialu zostało pokazane w sposób bardzo dosłowny, między innymi poprzez strach i obrzydzenie, jakie odczuwa Angela Abar, przeżywając traumę linczu, którego ofiarą padł jej dziadek. To zapośredniczone doznanie przypomina mechanizm postpamięci, definiowany przez Marianne Hirsch jako relacja łącząca

pokolenie biorące udział w doświadczeniu kulturowej lub kolektywnej traumy z kolejnym, które „pamięta” je wyłącznie dzięki opowieściom, obrazom i zachowaniom, wśród których

9 Ibidem, s. 8.

10 W elitarnym gronie Gwardzistów znaleźli się: Kapitan Metropolis (Nelson Gardner), Jedwabna Zjawa (Sally Jupiter), Nocny Puchacz (Hollis Mason), Dolarówka (William Brady), Człowiek-Ćma (Byron Lewis), Komediant (Edward Blake), Sylwetka (Ursula Zandt) i Zakapturzony Sędzia (w komiksie jego tożsamość pozostała zagadka). Zob. A. Moore, D. Gibbons, Strażnicy, przeł. J. Drewnowski, Wydawnictwo Egmont, Warszawa 2015, s. 67-70. W latach 60. grupa wznowiła działalność pod nową nazwą - Pogromcy Zbrodni (Crimebusters) - i w zmienionym składzie (dołączyli m.in. Doktor Manhattan, Ozymandiasz i Rorschach).

11 Zob. J. Bennett, Wnętrze, zewnętrza: trauma, afekt i sztuka, przeł. A. Kowalcze-Pawlik, T. Bilczewski, w: Pamięć i afekty, red. Z. Budrewicz, R. Sendyka, R. Nycz, Wydawnictwo IBL PAN, Warszawa 2014, s. $146,154$. 
dorastali. To doświadczenie zostało im przekazane w tak emocjonalny sposób, że wydaje się fundamentem ich własnej pamięci. [...] Dorastanie w kręgu tak potężnych, odziedziczonych wspomnień oraz opowieści o czasach, kiedy nas jeszcze nie było na świecie lub nie mieliśmy świadomości, co się wokół nas dzieje, niesie ze sobą niebezpieczeństwo wyparcia czy wręcz wymazania własnych opowieści i doświadczeń przez wspomnienia poprzedniego pokolenia ${ }^{12}$.

Pomimo sugerowanego przeze mnie pokrewieństwa łączącego pamięć protetyczną z postpamięcią - obie formy są odmianami pamięci zapośredniczonej, działają na podstawie afektywnego związku między przeszłością i teraźniejszością oraz pozwalają na doświadczenie wydarzeń, w których bezpośrednio nie brało się udziału - nie należy zapominać o różnicy między nimi: pamięć protetyczna nie wymaga międzypokoleniowego transferu, dlatego nie musi być przekazywana w obrębie rodziny ${ }^{13}$. Jednak w serialu Damona Lindelofa jest inaczej: pojęcia te uzupełniają się i przenikają, ponieważ technologicznie zapośredniczone (,wszczepione”) wspomnienia okazują się częścią rodzinnego dziedzictwa, którego w inny sposób nie można było przekazać.

Doświadczenie zastępcze, czyli całkowite utożsamienie się z przeżyciami drugiej osoby, może wywołać szereg zaburzeń osobowości. Z tego powodu bohaterka zostaje poddana tak zwanej „mnemodializie”, czyli terapii polegającej na usuwaniu cudzych wspomnień i oczyszczaniu pamięci z zewnętrznych naleciałości. Czy istnieje różnica między wspomnieniami ,autentycznymi” a tymi zapośredniczonymi technologicznie (w tym wypadku dzięki medycynie)? Alison Landsberg podkreśla, że choć pamięć protetyczna nie jest skutkiem przeżytych doświadczeń w tradycyjnym rozumieniu tego słowa - przypomina raczej sztuczną kończynę, protezę nałożoną na ciało - to jednak pozwala na przekroczenie granic rasowych, klasowych i płciowych. To dzięki niej można uzyskać dostęp do wiedzy, której inaczej by się nie posiadło, i odczuć bliskie pokrewieństwo z innymi ludźmi, doświadczyć tego samego, co oni ${ }^{14}$. Wspomnienia protetyczne odmieniają nasz stosunek do różnych spraw zarówno w wymiarze afektywnym, jak i politycznym. Moga podważyć dotychczasowe poglądy, ale również przyczynić się do odzyskania utraconego dziedzictwa, naprawienia zerwanych więzi międzypokoleniowych (nawet jeśli ich odbudowa prowadzi do konfrontacji z wiedzą o tym, co uczynili i kim naprawdę byli przodkowie).

Historia rodzinna splata się w serialu z historią społeczną, czyli opowieścią o prześladowaniach rasowych, walce z przestępczością i zmaganiach z przemocą symboliczną, która przejawia się w przemilczeniu niewygodnych faktów. Zyskując dostęp do nieznanych epizodów z życia własnej rodziny, Angela przekonuje się, że poznanie przeszłości odmienia teraźniejszość i pozwala spojrzeć na różne wydarzenia z niedostępnej wcześniej perspektywy - tworzy poniekąd alternatywny wariant

12 M. Hirsch, Pokolenie..., op. cit., s. 29.

13 Na podobieństwa i różnice między postpamięcią i pamięcią protetyczną zwraca uwagę Amy Kaminsky w artykule Memory, Postmemory, Prosthetic Memory: Reflections on the Holocaust and the Dirty War in Argentine Narrative, „Hispanic Issues On Line” 2014, Vol. 14, s. 112.

14 Zob. A. Landsberg, Prosthetic Memory..., op. cit., s. 21-22. 
znanej jej rzeczywistości. Jak pisze Anna Mach: „historia oddziałuje o tyle, o ile powtarza się i powraca jako to, co wyparte, przejawiając się w miejscach przesunięcia, przemieszczenia, może błędu" 15 .

Przyswajanie odległych wydarzeń w sposób zapośredniczony odciska piętno i odmienia człowieka nie tylko psychicznie, ale i fizycznie, ponieważ pamięć pozostawia ślady na ciele, czy może raczej należałoby powiedzieć: blizny po ,afektywnym zaangażowaniu" "'. Odnosi się to zwłaszcza do pamięci traumatycznej, w której wciąż na nowo przeżywa się wydarzenie graniczne, nie mogąc nabrać do niego dystansu. Bohaterka w bolesny sposób odczuwa dyskryminację, której doświadczył jej dziadek, i przekonuje się o tym, że doznania cielesne (jak wstręt czy mdłości) pozostają niekontrolowane. W alternatywnym świecie, w jakim osadzona jest akcja serialu - Stany Zjednoczone wygrały wojnę w Wietnamie, służby specjalne zatuszowały aferę Watergate i dzięki poprawce do konstytucji Richard Nixon pełnił funkcję prezydenta przez sześć kadencji - nadal działają organizacje białych suprematystów na wzór dawnego $\mathrm{Ku}$ Klux Klanu, których członkowie wyrażają niezadowolenie z powodu ustawy pozwalającej wypłacać odszkodowania dla ofiar prześladowań i ich potomków ${ }^{17}$.

Pamięć protetyczna jest w Watchmenach związana z dziedzictwem amerykańskiego rasizmu oraz próbą odzyskania tego, co utracone, a przynajmniej przypomnienia o stracie. Praca pamięci daje szansę ocalenia przeszłości przed zapomnieniem, uświadamia nam, że ,oficjalne uznanie krzywdy i symboliczne zadośćuczynienie ofiarom to często dopiero pierwszy krok, stanowiący warunek sine qua non w procesie przezwyciężenia skutków urazu"18. Na przekór lansowanej na początku nowego stulecia ideologii postrasowego społeczeństwa - Damon Lindelof postanowił pokazać w swoim serialu iluzoryczność tego projektu oraz uprzytomnić widzom konieczność powrotu do kwestii rasowych w dyskursie politycznym, społecznym i kulturowym ${ }^{19}$.

15 A. Mach, Świadkowie świadectw. Postpamięć Zagłady w polskiej literaturze najnowszej, Fundacja na rzecz Nauki Polskiej, Warszawa-Torun 2016, s. 68.

16 Alison Landsberg posługuje się pojęciem „,afektywnego zaangażowania” na określenie eksperymentalnego sposobu doświadczania przeszłości na poziomie taktylnym i materialnym poprzez „pobudzenie” ciała. Zob. A. Landsberg, Engaging the Past: Mass Culture and the Production of Historical Knowledge, Columbia University Press, New York 2015, s. 3.

17 W alternatywnej Tulsie działa Centrum Dziedzictwa Kulturowego Greenwood - rodzaj nowoczesnego muzeum, wzorowanego na otwartym w 2016 roku w Waszyngtonie National Museum of African American History and Culture - w którym można składać wnioski o odszkodowanie po wcześniejszym ustaleniu pokrewieństwa z mieszkańcami Greenwood z czasów masakry.

18 A. Mach, Świadkowie świadectw..., op. cit., s. 63.

19 Alison Landsberg łączy ideę postrasowości z okresem prezydentury Baracka Obamy oraz produkcjami filmowymi i telewizyjnymi z lat 2008-2015, w których podkreślano, że czynniki rasowe nie odgrywają już istotnej roli. Zob. A. Landsberg, Post-Postracial America: On Westworld and the Smithsonian National Museum of African American History and Culture, „Cultural Politics” 2018, Vol. 14, No. 2 , s. $199-200$. 
Twórcy udało się zrealizować założone cele między innymi dzięki „,prze-pisaniu” wątków zaczerpniętych z komiksu Alana Moore'a i Dave’a Gibbonsa. Niepewność co do prawdziwej tożsamości Zakapturzonego Sędziego pozwoliła na powiązanie tej postaci z Willem Williamsem, dzieckiem ocalałym z masakry w Tulsie, a dzięki temu na połączenie jego historii z opowieściami o zamaskowanych mścicielach z lat 40. Równie daleko idące konsekwencje dla interpretacji wydarzeń fabularnych miała przemiana Doktora Manhattana z niebieskiego półboga w czarnoskórego Calvina Abara (Yahya Abdul-Mateen II). Z jednej strony autorom chodziło o krytyczne nawiązania do nurtu blaxploitation movie, z drugiej zaś do komiksów z lat 70. z czarnoskórymi postaciami w rodzaju Czarnej Pantery, Brata Voodoo czy Luke'a Cage'a. Warto zwrócić uwagę na fakt, że rysunkowy wizerunek Misty Knight przypomina tytułową bohaterkę z filmu Sister Night, który w dzieciństwie oglądała Angela i z którego po latach zaczerpnęła swój pseudonim²0.

Pomysł odczytania postaci Zakapturzonego Sędziego i Doktora Manhattana w kluczu rasowym ma swój odpowiednik w strategii przyjętej przez Roberta Moralesa i Kyle'a Bakera, którzy w 2003 roku opublikowali siedmioodcinkową serię o przygodach pierwszego Kapitana Ameryka, zatytułowaną Truth: Red, White \& Black. Główny bohater komiksu, Isaiah Bradley, należał do dwustuosobowej grupy czarnoskórych mężczyzn, na których wojskowi lekarze w czasie II wojny światowej przeprowadzali eksperymenty w celu wyhodowania żołnierzy o nadludzkich możliwościach. Przystępując do dekonstrukcji mitu superbohaterskiego oraz demontażu rasistowskich stereotypów tkwiących u podstaw wielu opowieści tego typu, autorzy posłużyli się świadomą prowokacją - zwrócili uwagę na podobieństwo między stosunkiem amerykańskiego rządu do afroamerykańskiej mniejszości a działaniami podejmowanymi przez nazistów wobec społeczności żydowskiej²1.

Problem pamięci oraz przekazywania wiedzy o przeszłości jest w serialu znacznie bardziej skomplikowany i nie ogranicza się wyłącznie do kwestii rasistowskiego dziedzictwa Ameryki, ponieważ niemal wszyscy bohaterowie - niezależnie od pochodzenia etnicznego - zmagają się z traumatycznymi wspomnieniami, które

20 Siostra Noc jest filmem zaliczanym do nurtu blaxploitation, lecz - podobnie jak Zaufaj prawu! wymyślonym na użytek serialu. Misty Knight to była funkcjonariuszka nowojorskiej policji, która zadebiutowała w komiksie Marvela w 1975 roku. Czarna Pantera jest władcą fikcyjnego królestwa Wakandy i przypomina wyidealizowany wizerunek afrykańskiego przywódcy - jest nieprzekupny, wykształcony i sprawiedliwy. W latach 70. Marvel wydał serię Jungle Action, w której czarnoskóry superbohater walczył m.in. z członkami Ku Klux Klanu. Więcej informacji na temat afroamerykańskich postaci z komiksów przynosi książka Adilifu Namy Super Black: American Pop Culture and Black Superheroes, University of Texas Press, Austin 2011.

21 Zob. C. Francis, American Truths: Blackness and the American Superhero, w: The Blacker the Ink: Constructions of Black Identity in Comics and Sequential Art, eds. F. Gateward, J. Jennings, Rutgers University Press, New Brunswick 2015, s. 137. O rasistowskim podłożu komiksów o superbohaterach pisze także Aldo Regalado w Modernity, Race, and the American Superhero, w: Comics as Philosophy, ed. J. McLaughlin, University Press of Mississippi, Jackson 2005, s. 86. 
uniemożliwiają im prawidłowe funkcjonowanie w świecie ${ }^{22}$. Ich pamięć jest rozbita, pokawałkowana, jak gdyby żyli jednocześnie na kilku płaszczyznach czasowych, pozbawieni stabilnej tożsamości. Czerpiąc inspirację z oryginalnego komiksu, twórcy zdecydowali się na podważanie linearnego modelu czasu, a zarazem sproblematyzowanie związków między przeszłością, teraźniejszością i przyszłością, co wymusiło konieczność innego spojrzenia na kwestię pamięci.

Dla Doktora Manhattana czas jest iluzją - nic nie jest wcześniejsze ani późniejsze, jako że wszystkie wydarzenia rozgrywają się równocześnie ${ }^{23}$. Przeszłość, teraźniejszość i przyszłość są w równym stopniu realne, ponieważ z jego punktu widzenia rzeczywistość nie jest osadzona w czasie. Umowne są również określenia przestrzenne: „tutaj” - podobnie jak ,teraz” - jest złudzeniem, czy może raczej konwencją wynikającą z uwarunkowania ludzkiej percepcji. Patrząc na świat z perspektywy Doktora Manhattana, wydaje się, że wszystko jest stałe i niezmienne (jak u Parmenidesa). Odrzucenie możliwości zmiany pociąga za sobą eliminację pojęcia czasu, które okazuje się czymś zbędnym, w zasadzie nierealnym ${ }^{24}$. „Nie mogę zapobiec przyszłości. Dla mnie to już się dzieje” - mówi Doktor do Janey Slater w komiksie. „Wszystko jest z góry ustalone. Nawet moje reakcje" - powtórzy to innymi słowami w rozmowie z Laurie Juspeczyk ${ }^{25}$. Serialowym odpowiednikiem tych scen jest ,„pierwsze” spotkanie z Angelą - pokazane w odcinku ósmym - podczas którego bohater przedstawia swój „punkt widzenia” i uprzedza ją, że przeżyją szczęśliwie dziesięć lat, lecz ich małżeństwo zakończy się tragicznie.

Sposób rozumienia czasu przez Doktora Manhattana można wyjaśnić poprzez odniesienie do szczególnej teorii względności. Albert Einstein napisał, że „rozróżnienie pomiędzy przeszłością, teraźniejszością i przyszłościąjest niczym innym, jak uparcie podtrzymywaną iluzją"26. Od początku ubiegłego stulecia wielu fizyków i filozofów nauki zgadzało się z powyższą opinią, powtarzając, że czas jest wyłącznie pewnym złudzeniem, które wynika z tego, że nasz umysł skłania się do postrzegania zdarzeń jako uporządkowanych w czasie ${ }^{27}$. Jak tłumaczy Michał Heller: „Wrażenie pły-

22 Dotyczy to nie tylko Willa Williamsa, ale również jego wnuczki, która straciła rodziców w samobójczym zamachu bombowym Wade'a Tillmana (Tim Blake Nelson) - policyjnego partnera Angeli, posługującego się pseudonimem „Zwierciadło” - który w 1985 roku przeżył sfingowany przez Adriana Veidta atak istot z innego świata - oraz agentki FBI Laurie Blake (Jean Smart) - znanej niegdyś jako druga Jedwabna Zjawa - która nie może pogodzić się ze stratą Doktora Manhattana (w młodości była jego narzeczoną).

23 Należy zaznaczyć, że nie chodzi o równoczesność absolutną (newtonowską), lecz względną (einsteinowska), w której zdarzenia zachodzące równocześnie w jednym układzie odniesienia nie muszą być postrzegane jako takie w innym układzie.

24 Zob. J.M. Janowski, Zagadnienie istnienia i natury czasu w wybranych modelach kosmologicznych, Wydawnictwo Stowarzyszenia Filomatów, Warszawa 2016, s. 66.

25 A. Moore, D. Gibbons, Strażnicy, op. cit., s. 122, 281.

26 Cyt. za: J. Gołosz, Czy istnieje upływ czasu?, „Filozofia Nauki” 2010, nr 4(72), s. 98.

27 Zob. J.M.E. McTaggart, Nierealność czasu, przeł. M. Tempczyk, w: Ontologia. Antologia tekstów filozoficznych, red. M. Hempoliński, Ossolineum, Wrocław 1994, s. 362-368. 
nięcia czasu-przemijania powstaje w naszej świadomości, która tylko jakby w jednym punkcie styka się z czasoprzestrzenią $\mathrm{i}$ ten punkt styku nieustannie przesuwa się w kierunku, który nazywamy przyszłością (podobnie jak toczące się koło tylko w jednym punkcie swojego obwodu styka się z nieruchomą drogą)"28.

Już na pierwszy rzut oka widać rozdźwięk między intuicyjnym pojmowaniem kategorii czasowych a sposobem, w jaki funkcjonują one w fizyce relatywistycznej, zwłaszcza wśród zwolenników teorii wszechświata blokowego, jak David Hugh Mellor i Paul Davis ${ }^{29}$. Dla eternalistów - jak zazwyczaj określa się uczonych zaprzeczających realności czasu - wszystkie płaszczyzny temporalne są równorzędne pod względem ontologicznym, co niesie ze sobą określone konsekwencje nie tylko natury poznawczej, ale i egzystencjalnej, ponieważ upływ czasu łączy się z kwestią tożsamości osobowej oraz tożsamością rzeczy w otaczającym nas świecie ${ }^{30}$.

Nasze istnienie opiera się na silnym poczuciu trwałości przedmiotów i ludzi oraz pragnieniu stabilności, bez czego trudno wyobrazić sobie egzystencję, ale jeśli spojrzymy na świat oczami Doktora Manhattana, będziemy musieli przyznać, że niełatwo jest określić porządek zdarzeń na osi czasu. Chcąc zrozumieć jego sposób myślenia, należy zacząć od zakwestionowania przyjętego założenia, że wszelkie zjawiska mają swoją przyczynę i rozwijają się zgodnie z określonym kierunkiem. Żyjemy w przeświadczeniu, że czas jest nieodwracalny, że rozbite naczynie nie może odzyskać swojej wcześniejszej formy, że chcąc zaparzyć herbatę, trzeba najpierw zagotować wodę. Wydaje się, że istnienie „strzałki czasu”, która wskazuje jeden kierunek - od przeszłości do przyszłości, a nigdy odwrotnie - znajduje potwierdzenie w naszych wspomnieniach i przewidywaniach. Dla Doktora Manhattana wszystko to jest wyłącznie subiektywnym wrażeniem, które sprawia, że ludzie nie są w stanie postrzegać zjawisk inaczej niż w sposób narzucony im przez mózg, który porządkuje $\mathrm{i}$ interpretuje informacje oraz wytwarza poczucie ciagłości ${ }^{31}$.

Zgodnie z teorią wszechświata blokowego wydarzenia nie „stają się”, lecz „są”. „Nie doświadczam czegoś takiego, jak «zanim» - mówi Doktor Manhattan do Angeli Abar. - Wszystko po prostu jest”. Pragnąc wytłumaczyć jej, na czym polega wizja

28 M. Heller, Ontologiczne zaangażowania współczesnej fizyki, w: idem, Filozofia i wszechświat, Universitas, Kraków 2006, s. 143.

29 Zob. P. Davis, Czas. Niedokończona rewolucja Einsteina, przeł. L. Kallas, Prószyński i S-ka, Warszawa 2002. Nie zamierzam szerzej omawiać sporów o realność upływu czasu, jakie toczą prezentyści - przekonani o jego obiektywnym istnieniu - z eternalistami, dlatego zainteresowanych odsyłam do cytowanych przeze mnie prac Jerzego Gołosza i Jarosława Macieja Janowskiego.

30 Zob. J. Gołosz, Upływ czasu i ontologia, Wydawnictwo Uniwersytetu Jagiellońskiego, Kraków 2011, s. 105. Autor książki przedstawia argumenty, które przeczą sposobowi pojmowania czasu przez eternalistów.

31 Jak pisał Hermann Weyl, jeden z najwybitniejszych matematyków XX wieku: „Świat obiektywny po prostu jest, a nie się dzieje. To tylko moja świadomość, pełznąc wzdłuż linii świata mego ciała, ożywia wycinek świata jako przelotny obraz w przestrzeni, który w sposób ciaggły zmienia się w miarę upływu czasu". Cyt. za: L. Smolin, Czas odrodzony. Od kryzysu w fizyce do przyszłości wszechświata, przeł. T. Krzysztoń, Prószyński i S-ka, Warszawa 2015 (e-book). 
bezczasowego świata, bohater obrazowo opowiada, że dla niego wszystkie zdarzenia zachodzą (względnie) równocześnie, że siedzi razem z nią w wietnamskiej kawiarni w 2009 roku, zajmuje się terraformowaniem jednego z księżyców Jowisza, jest żydowskim dzieckiem, które ucieka z nazistowskich Niemiec w 1936 roku, oraz szczęśliwym mężem i ojcem trójki adoptowanych dzieci w 2019 roku.

Z perspektywy zdroworozsądkowej wydaje się, że to czas newtonowski - będący abstrakcyjną linią o wyznaczonym kierunku - prawidłowo opisuje porządek zdarzeń, jednak z punktu widzenia szczególnej teorii względności układ ten nie jest tak oczywisty, ponieważ strzałka czasu nie ma określonego kierunku i wszystko, co niegdyś zaszło, jest równie realne, jak to, co dopiero nastapi ${ }^{32}$. Można powtórzyć za Julianem Barbourem, że to „wspomnienia sprawiają, że jesteśmy obecni w tym, co nazywamy przeszłością, a nasze oczekiwania dają nam przedsmak tego, co nazywamy przyszłością" "33. Wydarzenia są przez nas zapamiętywane i jawią się jako uporządkowane chronologicznie - $\mathrm{i}$ to dzięki temu procesowi powstaje wrażenie przemijania - lecz nasze postrzeganie teraźniejszości ogranicza się wyłącznie do osobistych przeżyć.

Mimo że wszechświat Doktora Manhattana jest bezczasowy, wydaje się, że nie do końca funkcjonuje tak, jak rozumieją go eternaliści. Dla bohatera każdy moment życia jest chwilą aktualną, podczas gdy w teorii wszechświata blokowego nie ma miejsca na chwile aktualne, które zastapione są przez zdarzenia punktowe (jak w czasoprzestrzeni Minkowskiego). Jego świat jest bezczasowy w tym sensie, że nic nowego się w nim nie „dzieje”, że wszystkie zdarzenia ,już tam są” (choć nie tworzą linearnego ciagu, jak w ujęciu newtonowskim). „Obraz nas samych rozdzielonych na równoległe chwile aktualne może być niepokojący, ale samo zjawisko jest dobrze znane - powiada Julian Barbour. - Jesteśmy przyzwyczajeni do istnienia w różnych chwilach aktualnych i istnienia w nieco innej formie w każdej z nich - jest to po prostu efekt upływu czasu, jak się go zwykle pojmuje"34.

Doświadczenie trwania jest czymś wtórnym, co pojawia się jedynie w naszej świadomości. Wrażenie ciagłości wzmacniają „kapsuły czasu” - jak nazywa je Barbour - czyli zapisy tego, co minęło, a co postrzegane było przez nas jako rozgrywające się „tu i teraz”. Zapisy te są dla nas realne i stanowią przyczynę naszej wiary w zjawisko czasu. „Cała wiedza dotycząca przeszłości w istocie zawiera się właśnie w owych zapisach. Im bardziej przeszłość staje się realna i namacalna, tym większa spójność zapisów pamięciowych"35. Zapis to struktura, która wydaje się opowiadać spójną historię

32 Zob. H. Price, Strzałka czasu i punkt Archimedesa. Nowe kontrowersyjne spojrzenie na czas $i$ wspótczesna fizykę, przeł. P. Lewiński, Amber, Warszawa 1998.

33 J. Barbour, Koniec czasu. Nowa rewolucja w fizyce, przeł. T. Lanczewski, Copernicus Center Press, Kraków 2018 (e-book).

34 Ibidem. Szukając argumentów przemawiających za koncepcją bezczasowego wszechświata, Barbour odwołuje się do teorii względności Einsteina, zasady Macha, funkcji falowej, równań Schrödingera oraz Wheelera-DeWitta.

35 Ibidem. 
- jak ludzka pamięć lub układ pojedynczych klatek filmowych, tworzących podczas projekcji kinowej wrażenie płynności ruchu i ciągłości czasu ${ }^{36}$.

Pozostaje zadać pytanie o to, czy pamięć w ogóle istnieje, skoro nieodłącznie związana jest z czasem i dotyczy przeszłych doświadczeń, na podstawie których próbujemy przewidzieć to, co może nastapić w przyszłości. Jak twierdzi Dean Buonomano, autor książki Your Brain Is a Time Machine, wielu neurobiologów i neuropsychologów zgodziłoby się co do tego, że nasze poczucie czasu jest złudzeniem i to mózg wytwarza dla nas tę iluzję. Podstawowy problem polega jednak na tym, że słowo „złudzenie" rozumiane jest inaczej przez eternalistów, którzy sugeruja, że upływ czasu jest doświadczeniem subiektywnym, a nie cechą świata zewnętrznego, inaczej zaś przez przedstawicieli neuronauki. Ci drudzy akceptują twierdzenie, że czas jest konstrukcją mentalną, lecz od razu dodają, że taką, która wiarygodnie - choć w sposób niedoskonały - odzwierciedla zjawiska fizyczne zachodzące w świecie materialnym $^{37}$. Człowiekowi łatwiej jest uwierzyć w możliwość przemieszczania się między przeszłością, teraźniejszością i przyszłością, niż zaakceptować tezę o nierealności czasu. Można powiedzieć, że eternaliści nie przyjmują „ludzkiej” perspektywy, lecz patrzą na świat z punktu widzenia Doktora Manhattana, którego umysł jest zdolny do uchwycenia zależności zachodzących na poziomie czterowymiarowej areny zdarzeń.

Przeświadczenie o nierealności czasu nie jest wyłącznie atrybutem nieludzkiego bohatera serialu, ponieważ podobne doznania występują u osób, które przeżyły traumę i doświadczają nieciagłości czasu, czyli rozerwania związku między przeszłością, teraźniejszością i przyszłością, wskutek czego ich poczucie „bycia-w-czasie” ulega dezintegracji ${ }^{38}$. Traumatyczne historie zawsze rozgrywają się poza porządkiem linearnym, a wspomnienia o nich nie tworzą zintegrowanej pamięci, dlatego w serialu wielokrotnie powraca scena masakry w Tulsie, zazwyczaj przywoływana w postaci krótkiej wstawki, która przypomina o widmowej obecności zmarłych ${ }^{39}$. Jeśli traumatycznego przeżycia nie można umiejscowić w porządku chronologicznym, to opowiedzenie o nim wymaga znalezienia odpowiednich narzędzi, zdolnych do uchwycenia rozbitej i pokawałkowanej tożsamości. Pamięć traumatyczna - podobnie jak

36 Metaforą nieruchomych klatek filmowych, które podczas projekcji tworzą wrażenie ruchu i ciagłości czasu, posłużył się nie tylko Julian Barbour, ale również Brian Greene w książce Struktura kosmosu. Przestrzeń, czas i struktura rzeczywistości, przeł. E.L. Łokas, Prószyński i S-ka, Warszawa 2005.

37 Zob. D. Buonomano, Your Brain Is a Time Machine: The Neuroscience and the Physics of Time, W.W. Norton \& Company, New York 2017, s. 173. Żyjemy w świecie doznań subiektywnych, a nasze zdolności postrzegania kolorów, słyszenia muzyki, czucia zapachów są przykładami konstrukcji mentalnych - pisze Buonomano - czyli złudzeniami, z których każde ma jednak swoje źródło w rzeczywistych zjawiskach fizycznych, jak długość fal elektromagnetycznych, fale dźwiękowe i struktura chemiczna cząsteczek.

38 Zob. M. Bush, Refractions in Time: A Minkowskian Understanding of Being Dislocated in Time, „Existential Analysis” 2020, Vol. 31, No. 1, s. 134-135, 138.

39 W ujęciu Jacques'a Derridy obecność widm świadczy o rozbiciu linearnego czasu, jest doświadczeniem ,,przeszłości jako tego, co nadchodzi (à venir)”. J. Derrida, Widma Marksa, przeł. T. Załuski, Wydawnictwo Naukowe PWN, Warszawa 2016, s. 14. 
sposób percepcji świata przez Doktora Manhattana - polega na wrażeniu równoczesności zdarzeń, które w „normalnych” warunkach postrzegane byłyby jako następujące po sobie. Potwierdzają to holenderscy psychologowie, Bessel A. van der Kolk i Onno van der Hart, którzy piszą: ,,symultaniczność łączy się z tym, że traumatyczne doświadczenie jest w pewnym sensie bezczasowe. Nie uległo przekształceniu w historię osadzoną w czasie, posiadającą początek, środek i koniec (co jest charakterystyczną właściwością pamięci narracyjnej)"40. Przeżyta trauma sprawia, że człowiek odnosi wrażenie, że istnieje niejako poza czasem, że jego świat jest statyczny - nic się w nim nie porusza, nic się nie zmienia i ,nic się nigdy nie kończy”41.

\section{Bibliografia}

Barbour J., Koniec czasu. Nowa rewolucja w fizyce, przeł. T. Lanczewski, Copernicus Center Press, Kraków 2018.

Bennett J., Wnętrze, zewnętrza: trauma, afekt i sztuka, przeł. A. Kowalcze-Pawlik, T. Bilczewski, w: Pamięć i afekty, red. Z. Budrewicz, R. Sendyka, R. Nycz, Instytut Badań Literackich PAN, Warszawa 2014, s. 145-179.

Brophy A.L., Reconstructing the Dreamland: The Tulsa Riot of 1921, Oxford University Press, New York 2002.

Buonomano D., Your Brain Is a Time Machine: The Neuroscience and the Physics of Time, W.W. Norton \& Company, New York 2017.

Bush M., Refractions in Time: A Minkowskian Understanding of Being Dislocated in Time, „Existential Analysis” 2020, Vol. 31, No. 1, s. 133-141.

Davis P., Czas. Niedokończona rewolucja Einsteina, przeł. L. Kallas, Prószyński i S-ka, Warszawa 2002.

Derrida J., Widma Marksa, przeł. T. Załuski, Wydawnictwo Naukowe PWN, Warszawa 2016.

Francis C., American Truths: Blackness and the American Superhero, w: The Blacker the Ink: Constructions of Black Identity in Comics and Sequential Art, eds. F. Gateward, J. Jennings, Rutgers University Press, New Brunswick 2015, s. 137-152.

Gołosz J., Czy istnieje upływ czasu?, „Filozofia Nauki” 2010, nr 4(72), s. 97-120.

Gołosz J., Upływ czasu i ontologia, Wydawnictwo Uniwersytetu Jagiellońskiego, Kraków 2011.

Greene B., Struktura kosmosu. Przestrzeń, czas i struktura rzeczywistości, przeł. E.L. Łokas, Prószyński i S-ka, Warszawa 2005.

Heller M., Ontologiczne zaangażowania wspótczesnej fizyki, w: idem, Filozofia i wszechświat, Universitas, Kraków 2006.

Hirsch M., Pokolenie postpamięci, przeł. M. Borowski, M. Sugiera, „Didaskalia” 2011, nr 105, s. 28-36.

40 B.A. van der Kolk, O. van der Hart, The Intrusive Past: The Flexibility of Memory and the Engraving of Trauma, w: Trauma: Explorations in Memory, ed. C. Caruth, The Johns Hopkins University Press, Baltimore 1995, s. 177.

41 To ostatnie słowa Doktora Manhattana skierowane do Adriana Veidta („Ozymandiasza”) w komiksie Moore'a i Gibbonsa Strażnicy, op. cit., s. 405. 
Janowski J.M., Zagadnienie istnienia i natury czasu $w$ wybranych modelach kosmologicznych, Wydawnictwo Stowarzyszenia Filomatów, Warszawa 2016.

Kaminsky A., Memory, Postmemory, Prosthetic Memory: Reflections on the Holocaust and the Dirty War in Argentine Narrative, „Hispanic Issues On Line” 2014, Vol. 14, s. 104-117.

Kuhn A., Memory Texts and Memory Work: Performances of Memory in and with Visual Media, „Memory Studies” 2010, Vol. 3, No. 4, s. 298-313.

LaCapra D., Historia w okresie przejściowym. Doświadczenie, tożsamość, teoria krytyczna, przeł. K. Bojarska, Universitas, Kraków 2009.

Landsberg A., Engaging the Past: Mass Culture and the Production of Historical Knowledge, Columbia University Press, New York 2015.

Landsberg A., Post-Postracial America: On Westworld and the Smithsonian National Museum of African, „Cultural Politics” 2018, Vol. 14, No. 2, s. 198-215.

Landsberg A., Prosthetic Memory: The Transformation of American Remembrance in the Age of Mass Culture, Columbia University Press, New York 2002.

Mach A., Świadkowie świadectw. Postpamięć Zagłady w polskiej literaturze najnowszej, Fundacja na rzecz Nauki Polskiej, Warszawa-Toruń 2016.

McTaggart J.M.E., Nierealność czasu, przeł. M. Tempczyk, w: Ontologia. Antologia tekstów filozoficznych, red. M. Hempoliński, Ossolineum, Wrocław 1994, s. 362-368.

Moore A., Gibbons D., Strażnicy, przeł. J. Drewnowski, Wydawnictwo Egmont, Warszawa 2015.

Nama A., Super Black: American Pop Culture and Black Superheroes, University of Texas Press, Austin 2011.

Price H., Strzałka czasu i punkt Archimedesa. Nowe kontrowersyjne spojrzenie na czas $i$ współczesna fizykę, przeł. P. Lewiński, Amber, Warszawa 1998.

Regalado A., Modernity, Race, and the American Superhero, w: Comics as Philosophy, ed. J. McLaughlin, University Press of Mississippi, Jackson 2005, s. 84-99.

Smolin L., Czas odrodzony. Od kryzysu w fizyce do przyszłości wszechświata, przeł. T. Krzysztoń, Prószyński i S-ka, Warszawa 2015.

van der Kolk B.A., van der Hart O., The Intrusive Past: The Flexibility of Memory and the Engraving of Trauma, w: Trauma: Explorations in Memory, ed. C. Caruth, The Johns Hopkins University Press, Baltimore 1995, s. 158-182. 